\title{
Improved survival after orthotopic liver grafting
}

\author{
R Y CALNE, ROGER WILLIAMS, M LINDOP, J V FARMAN, M E TOLLEY, K ROLLES, \\ B MACDOUGALL, J NEUBERGER, R J WYKE, A T RAFTERY, T J DUFFY, D G D WIGHT, \\ D J G WHITE
}

\begin{abstract}
A total of 108 orthotopic liver transplants have been carried out in the Cambridge/King's College Hospital series. Over 13 years, changes in patient selection, immunosuppression, and surgical and anaesthetic techniques have led to a steady improvement in results. Results obtained in the last 22 patients indicated that over half survive for one year. Although at considerable risk during the operation, patients with non-malignant cirrhotic diseases who survive one year have a good long-term chance of survival.
\end{abstract}

A slow but steady improvement in survival after liver grafting has resulted from multiple and interacting factors. These include patient selection; technical changes, particularly regarding biliary drainage; increased availability of donors with transport of livers between different centres; and new immunosuppressive management.

Although patients with primary carcinoma of the liver are better operative risks, the incidence of recurrent growth is about $60 \%$. Patients with non-malignant cirrhotic disease are more apt to develop perioperative complications, but having survived the first few weeks their chances of long-term rehabilitation are better than are those of patients with malignant conditions. Many of the earlier patients in this series would now be considered too ill for the procedure, but still about half of the patients accepted for grafting die before a donor liver becomes available, and some patients who are suitable when first seen are gravely ill by the time a liver graft can be performed.

We summarise the results and experience gained from the 108 orthotopic liver transplants performed in the Cambridge/ King's College Hospital series from May 1968 to May 1981.

K ROLLES, MB, FRCS, lecturer and honorary senior registrar

A T RAFTERY, MD, FRCS, lecturer and honorary consultant surgeon

T J DUFFY, BM, FRCS, lecturer and honorary senior registrar

D J G WHITE, MA, PHD, research associate

Liver Unit, King's College Hospital, London

ROGER WILLIAMS, MD, FRCP, director

B MACDOUGALL, MB, MRCP, senior registrar

J NEUBERGER, BM, MRCP, research fellow

R J WYKE, MB, MRCP, research fellow

Department of Anaesthetics, Addenbrooke's Hospital, Cambridge

M LINDOP, MB, FFARCS, consultant anaesthetist

J V FARMAN, FFARCS, consultant anaesthetist

ME TOLLEY, MB, FFARCS, consultant anaesthetist

Department of Pathology, Addenbrooke's Hospital, Cambridge D G D WIGHT, MB, MRCPATH, consultant pathologist

\author{
Indications and restrictions for grafting \\ AGE \\ We have not been able to obtain livers from children and, therefore, \\ cannot offer this operation to patients with biliary atresia. Previously, \\ the side effects of steroids were a further contraindication to grafting \\ children but immunosuppression with cyclosporin $\mathrm{A}$ does not usually \\ require additional long-term steroids. ${ }^{1}$ The surgical risks are greater \\ for patients over 55 . Thus our policy is to consider only patients past \\ puberty and under 55 .
}




\section{Pathology of the non-malignant conditions}

Most of our cases have been of non-alcoholic aetiology, as alcoholic patients tend to be unreliable in hospital attendance and taking medication. Primary biliary cirrhosis, chronic active hepatitis, and the Budd-Chiari syndrome are the most common indications for liver grafting. Australia antigenaemia is a relative contraindication because of the risk to the staff and also the danger to the graft from reinfection. For prevention of the latter, hyperimmune globulin is given to the patient during the anhepatic phase, and one of our patients is well at five and a half years and the blood has remained antigen free. ${ }^{2}$ Recrudescence of the patient's original disease in the graft is a possibility in any cirrhotic disease with a primary autoimmune basis. Evidence to suggest that this may occur has been obtained recently in three patients transplanted for primary biliary cirrhosis. The first signs were observed during the third year after grafting (J Neuberger et al, unpublished observations). The use of possibly hepatotoxic immunosuppressive drugs can be a complicating factor, and the distinction from one of the clinical varieties of chronic rejection may be difficult. Patients who had suffered from the BuddChiari syndrome are kept anticoagulated with warfarin, since, in a case when this was not done, the hepatic veins rethrombosed.

Of the malignant conditions, primary hepatocellular carcinoma and cholangiocarcinoma arising within the liver constitute the largest group. Scirrhous carcinoma arising at the junction of bile ducts in porta hepatitis (Klatskin tumour) and hepatic secondary deposits are not suitable; our experience has shown that there is usually rapid recurrence of these tumours.

\section{Assessment}

For patients with non-malignant disease, liver grafting should be considered when it is realised that the disease is preventing the patient from living a satisfactory life. Recurrent variceal bleeding, incapacitating encephalopathy, or weakness making the patient bedridden or housebound are specific instances. We admit the patients to hospital for assessment and to enable them to meet the nurses and doctors who will look after them. If the patient is medically suitable and he and his relatives have fully understood the risks of the procedure, he is accepted for transplantation.

A systolic blood pressure below $100 \mathrm{~mm} \mathrm{Hg}$, infection, severe impairment of clotting tests, and a blocked portal vein are contraindications. For patients with liver cancer a biopsy is required to confirm the diagnosis. Intravenous pyelography and barium studies of the gastrointestinal tract are performed to exclude an occult primary cancer in the kidney or colon, because these two sites are the most likely to give rise to hepatic metastases, which may be difficult to distinguish from primary hepatocellular carcinoma or cholangiocarcinoma. Abdominal computerised and skeletal scanning and tomography of both lungs are also carried out to exclude extrahepatic metastases, but micrometastases (particularly in lymph nodes within the porta hepatis) will not be detected, and this risk must be accepted.

\section{The operation}

The operation has been described in detail elsewhere. ${ }^{3} \mathrm{~A}$ team of surgeons, anaesthetists, nurses, and technicians familiar with the procedure require the active support of a well-staffed blood bank and biochemical laboratory. The criteria for a suitable donor are a compatible ABO red cell group, no systemic infection or malignancy, no history of liver disease or alcoholism, normal liver function test results, and the absence of Australia antigenaemia. The operation takes two to three hours of careful dissection with the circulation intact in a donor who has died as a result of cerebral destruction. Overhydration of the donor and excessive infusion of cooling fluid of extracellular ionic content through the portal vein combined with hypotension may give rise to an oedematous, ischaemically damaged liver that will not perfuse when grafted. The kidneys are also removed for grafting. The liver is cooled by perfusion through the portal vein and hepatic artery. Bile from the gall bladder and major bile ducts is washed with cold perfusate. Since this modification was introduced two years ago there have been no cases of sloughing of the biliary epithelium that had often caused obstruction of bile flow. ${ }^{4}$ While the liver is cold and unperfused on an operating "work bench" the gall bladder is mobilised and the common bile duct is anastomosed to an incision in Hartman's pouch, this anastomosis being splinted with a T tube. This is done either before or after the liver has been stored in ice (fig). The liver may be kept cold for up to 10 hours; it is possible, therefore, to transport livers long distances by car or air. In the past year livers have been removed by transplant teams in Holland, Germany, and England and sent by air to liver transplant teams in Groningen, Hanover, and Cambridge, where they have been grafted successfully. Storage and transportation of the donor liver increase the chances of a patient receiving a transplant.

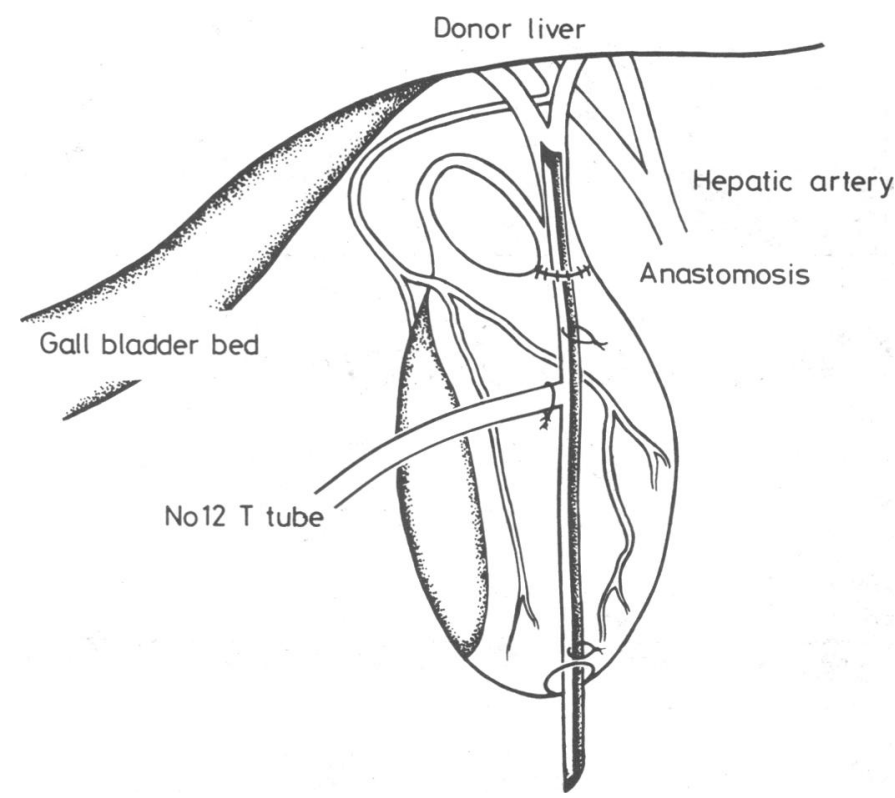

Diagram of "bench surgery," in which gall bladder is mobilised and Hartmann's pouch is anastomosed to donor common bile duct and a guttered $T$ tube is used to splint this anastomosis. The procedure is performed with the liver cold either before or after preservation period.

The recipient operation may be difficult owing to portal hypertension, impaired clotting, and vascular adhesions from any previous surgery. All bleeding points are ligated with sutures. Trial clamping of the inferior vena cava below the liver will give the anaesthetist an indication of the patient's ability to withstand removal of the liver. Partial cardiopulmonary bypass is now seldom required because patients are accepted for surgery slightly earlier in the course of their disease. $^{5}$

\section{Postoperative care and immunosuppression}

Prophylactic gentamicin and metroniadazole are given for two days. The patient is nursed in an intensive care area for five days, by which time the drains and invasive catheters should have been removed. Azathioprine $1.5 \mathrm{mg} / \mathrm{kg} /$ day and prednisolone $0.4 \mathrm{mg} / \mathrm{kg} /$ day are given until renal and hepatic function are adequate; cyclosporin A $10 \mathrm{mg} / \mathrm{kg} /$ day is then substituted for the azathioprine and the steroid dose is slowly reduced to zero. ${ }^{1}$ Samples of blood, urine, sputum, bile, faeces, and the surgical wound are cultured frequently. Bile is allowed to drain from the $T$ tube for 10 days. If a $T$-tube cholangiogram shows adequate drainage the tube is spigotted and left in situ for two to three months, after which it is removed.

\section{Diagnosis of rejection and follow-up}

A decrease in serum bilirubin, alkaline phosphatase, and transaminase concentrations to normal indicates a satisfactory course. A subsequent increase in any or all of these may indicate rejection, which occurs in many patients five to 14 days postoperation. There may be an associated leucocytosis and fever, and the bile usually changes colour from normal dark green to light orange or yellow. Absence of biliary obstruction or breakdown of anastomosis is confirmed by a T-tube cholangiogram. The leucocyte migration test using donor antigen may be helpful, and if the patient's coagulation test results are 
normal a needle biopsy of the liver is carried out. If rejection occurs the patient is treated with increased doses of steroids. ${ }^{3}$

Patients with satisfactory progress are allowed up at one week and are discharged from hospital with the $T$ tube spigotted three to six weeks postoperatively.

\section{Results}

Of the 108 recipients of liver allografts over the past 13 years, 20 are alive and 15 of these have survived more than six months; six are alive at between four and five and a half years. Of the 100 patients transplanted more than six months ago, 36 survived beyond six months (table I) and the one-year survival calculated from the 93 patients who were grafted more than a year ago was $24 \%$. This contrasts with an earlier one-year survival figure of $13 \%$, which was calculated from 46 patients transplanted more than five years ago. In the early phase of this programme most of the deaths resulted from complications of biliary drainage, perioperative haemorrhage, and acute heart failure. Of those grafted for malignant disease who survived six months, $60 \%$ succumbed to recurrence of tumour. Of the 22 patients grafted in the past 21 months, 13 are alive one week to 18 months later, giving a current one-year survival rate of over $50 \%$. Two patients died from bleeding before the operation could be completed. The causes of death in nine of the last 22 cases are listed in table II. Septicaemia is now the main lethal complication, and the four patients who died were still receiving azathioprine and steroids. Three had been given high steroid dosage because of rejection. We now plan to change patients to cyclosporin $\mathrm{A}$ in the first week after grafting before

TABLE I-Cases surviving over six months

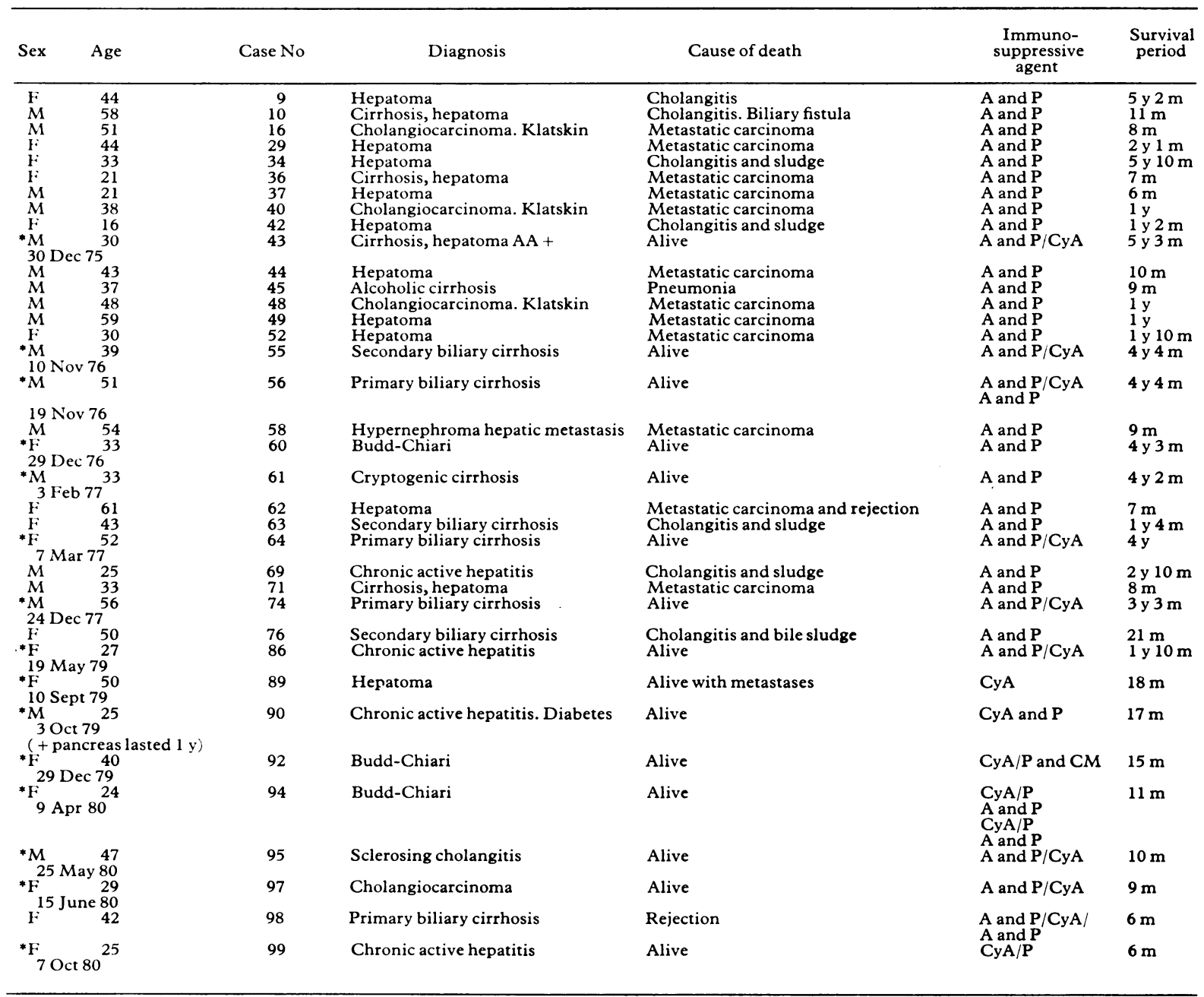

*Patients alive. $\quad \mathrm{A}=$ Azathioprine. $\mathrm{P}=$ Prednisone. $\mathrm{CyA}=$ Cyclosporin $\mathrm{A} . \quad \mathrm{CM}=\mathrm{Cytamen}$ (cyanocobalamin).

TABLE II-Cause of death: nine of last 22 cases

\begin{tabular}{|c|c|c|c|c|c|c|}
\hline Case No & Sex & Age & Diagnosis & Day & $\begin{array}{c}\text { Immunosuppressive } \\
\text { agent }\end{array}$ & Cause of death \\
\hline $\begin{array}{r}87 \\
88 \\
91 \\
93 \\
96 \\
98 \\
100 \\
102 \\
103\end{array}$ & $\begin{array}{l}\mathrm{F} \\
\mathrm{M} \\
\mathrm{F} \\
\mathrm{F} \\
\mathrm{M} \\
\mathrm{F} \\
\mathrm{F} \\
\mathrm{M}\end{array}$ & $\begin{array}{l}31 \\
56 \\
23 \\
40 \\
29 \\
42 \\
28 \\
54 \\
36\end{array}$ & $\begin{array}{l}\text { Cholangiocarcinoma } \\
\text { Hepatoma } \\
\text { Caroli's Syndrome } \\
\text { Primary biliary cirrhosis } \\
\text { Sclerosing cholangitis } \\
\text { Primary biliary cirrhosis } \\
\text { Chronic active hepatitis } \\
\text { Cryptogenic cirrhosis } \\
\text { Primary biliary cirrhosis }\end{array}$ & $\begin{array}{c}17 \\
3 \\
11 \\
69 \\
37 \\
6 \text { months } \\
9 \\
3 \\
47\end{array}$ & $\begin{array}{l}A \text { and } P \\
\text { Intravenous steroid only } \\
\text { CyA } \\
C y A / A \text { and } P \\
A \text { and } P \\
A \text { and } P / C y A / A \text { and } P \\
A \text { and } P \\
A \text { and } P \\
A \text { and } P\end{array}$ & $\begin{array}{l}\text { Septicaemia } \\
\text { Continuing perioperative haemorrhage } \\
\text { Respiratory arrest } \\
\text { Rejection } \\
\text { Septicaemia } \\
\text { Chronic rejection } \\
\text { Septicaemia } \\
\text { Subdural haematoma } \\
\text { Septicaemia }\end{array}$ \\
\hline
\end{tabular}

A $=$ Azathioprine $. \quad \mathbf{P}=$ Prednisone. $\quad$ CyA $=$ Cyclosporin $\mathbf{A}$. 
rejection is likely to occur, since bacterial infection has been less common in our renal allograft recipients treated with cyclosporin A than in those treated with azathioprine and prednisolone.

Rehabilitation in survivors who have left hospital has been excellent, but continuing bone pain and osteoporosis in cirrhotic patients with pre-existing bone disease has been aggravated by the steroids. This complication should become less common with the increasing use of cyclosporin A.

\section{Discussion}

The results of orthotopic liver allografting have slowly improved. Our experience is similar to that in Denver, where about 200 patients have received liver grafts. ${ }^{\circ}$ Starzl's longest survivor is well after more than 10 years, and two of his female patients have given birth to normal children after liver transplantation. ${ }^{7}$ The perioperative mortality of patients with primary malignancy of the liver is below that of cirrhotic patients because the former usually have good liver function in the non-affected hepatic parenchyma. The cancer recurrence rate of $60 \%$ in patients surviving six months, however, has prompted us to change from operating predominantly on malignant cases to mainly cirrhotic patients. More cirrhotic patients would have a chance for a transplant if they were referred earlier in the terminal course of their disease and if surgeons removing kidneys for transplantation would be prepared to help with liver donation from the same donor. A cirrhotic patient who survives a year has a good chance of long survival. The possible recurrence of disease when the transplant is carried out for primary biliary cirrhosis has already been referred to (J Neuberger et al, unpublished observations). So far, however, the disease manifestations have been mild. Starzl has also observed recurrence of sclerosing cholangitis in a grafted liver at 11 months (personal communication).
Although a formidable procedure, transplantation of the liver may give excellent rehabilitation to young patients for whom there is no alternative treatment. The costs and use of resources may well be less than those of prolonged care in hospital of patients dying of liver diseases. In economic terms liver grafting is sound if the patient is restored to useful activity; in human terms no justification is necessary.

We thank our medical, nursing, and technical colleagues at Addenbrooke's and King's College Hospital and our colleagues in Groningen and Hanover for their co-operation in removing and transporting livers. We are especially grateful to the staff in other hospitals in the United Kingdom, Holland, and Belgium who have informed us of suitable donors. We are grateful to the air crews who have transported the livers.

\section{References}

${ }^{1}$ Calne RY, White DJG, Evans DB, et al. Cyclosporin A in cadaveric organ transplantation. $\mathrm{Br} \mathrm{Med} \mathrm{f} 1981 ; 282$ :934-6.

${ }^{2}$ Johnson PJ, Wansbrough-Jones MH, Portmann B, Eddleston ALWF, Williams R. Familial HBsAg positive hepatoma: treatment with orthotopic liver transplantation and specific immunoglobulin. $\mathrm{Br} \mathrm{Med} \mathfrak{f}$ $1978 ; \mathrm{i}: 216$.

${ }^{3}$ Calne RY, Williams R. Liver transplantation. Current problems in surgery. $1979 ; X V I: 22$.

4 McMaster P. Bile studies after liver transplantation. Ann $R$ Coll Surg Engl 1979;61:435-40.

${ }^{5}$ Calne RY, McMaster P, Smith DP, et al. Use of partial cardiopulmonary bypass during the anhepatic phase of orthotopic liver grafting. Lancet 1979 ;ii:612-4.

6 Starzl TE, Iwatsuki S, Klintmalm G, et al. Liver transplantation, 1980, with particular reference to cyclosporin A. Transplant Proc 1981;13: 281-5.

${ }^{7}$ Penn I, Makowski EL. Parenthood in kidney and liver transplant recipients. Transplant Proc 1981 ;13:36-9.

(Accepted 20 May 1981)
What are the chances of an abnormality developing in the infant of a woman who was taking the oral contraceptive norethisterone acetate (Norlestrin) during the first three months of pregnancy?

Norlestrin, in Britain and Australia, consists of $2.5 \mathrm{mg}$ norethisterone acetate and $0.05 \mathrm{mg}$ ethinyloestradiol. It is a standard "combined" oral contraceptive, with no greater or smaller chance of causing fetal abnormality than any other such preparation. The question of whether or not oral contraceptives cause fetal abnormality is difficult to answer, and the risk is not substantiated. ${ }^{1}$ Although administration of some oestrogens or progestogens to pregnant rats may cause abnormalities of sex differentiation, combined preparations in animals have not shown teratogenicity. ${ }^{2}$ Women becoming pregnant after stopping the pill do not appear to have an increased chance of fetal abnormality. Among women taking hormones in early pregnancy (either inadvertently or as a treatment for threatened abortion) many possible abnormalities have been reported, including cardiac, ${ }^{3}$ limb reduction, and genital anomalies. ${ }^{24}$ More than one acronym has been invented to describe these, ${ }^{4}$ but a definite relationship with oral contraceptives has not been proved. There are no reports of delayed effects as infants grow up after intrauterine exposure to sex hormones, except for the well-known effects of diethylstilboestrol. One wonders whether conclusive information will ever become available, but in the meantime current practice is to discontinue the use of hormonal pregnancy tests, to be cautious in using hormones to treat or "prevent" threatened abortion, and to reassure pregnant women who have inadvertently taken the pill that the risk of fetal abnormality is either extremely low or non-existent. 1. Vessey MP. Contraceptive methods: risks and benefits. Br Med I 1978;ii :721-2.
3 Ambani LM, Joshi NJ, Vaidya RA, Devi PK. Are hormonal contraceptives Ambani LM, Joshi NJ, Vaidya RA, Devic

3 teratogenic? Funerich DT, Dugan JM, Standfast SJ, Strite L. Congenital heart disease and 3 Janerich DT, Dugan $3 M$, Standfast 3 , Strites.

- prenatal exposure to exogenous sex hormones. exposure syndrome (EFFESSES)? Fertil Steril 1979;31:21-4.
Recent reports show that carcinoma of the thyroid gland can be initiated after comparatively low doses of irradiation. How much irradiation of the thyroid occurs during procedures for soft tissue radiography of the neck or the usual anteroposterior and lateral radiographs for investigating lesions of the cervical spine pathology?

The radiation dose to the thyroid from radiography of the cervical spine or soft tissues of the neck may be calculated by applying Rosenstein's ${ }^{1}$ system for estimating organ doses to the skin doses from diagnostic radiology described by Rogers. ${ }^{2}$ Thus a typical examination of the cervical spine entailing three radiographs probably results in a dose to the thyroid of around 100 mrads. The risk of radiation carcinogenesis is assumed to be linear with dose and to be without threshold. The induction rate for radiogenic thyroid carcinomas appears to be somewhat higher in females than in males and is probably rather higher in infants and children than in adults. ${ }^{3}$ Although the induction rate of thyroid malignancies within 25 years of the time of irradiation is high (50-150 cases per million per rad) compared with other radiationinduced cancers, these tumours have a low mortality, the mortality risk factor being around 10 per million per rad. ${ }^{3}$ Thus an examination necessitating a thyroid dose of 100 mrads will carry a risk of around one in a million of developing a subsequent fatal malignancy due to the radiation. Although an excess of thyroid cancer has been reported after therapeutic irradiation of the skin of the scalp, and the resultant radiation doses to the thyroid of the order of 5-10 rads, it is most improbable that the risks associated with doses of around 100 mrads would be demonstrable by epidemiological techniques.

${ }^{1}$ Rosenstein M. Organ doses in diagnostic radiology. Rockville, Md: US Department of Health Education and Welfare, Bureau of Radiological Health, 1976. (HEW Publication (FDA) 76-8030.)

Rogers RT. Radiation dose to the skin in diagnostic radiography. Br $\mathcal{F}$ Radio $1969 ; 42: 511-8$.

${ }^{3}$ United National Scientific Committee on the Effects of Atomic Radiation. Causes and effects of ionising radiation. New York: United Nations, 1977:377-85. (United Nations Scientific Committee on the effects of atomic radiation 1977 report to the General Assembly, with annexes.) 